Research Article

\title{
Study on Ammonia-induced Catalyst Poisoning in the Synthesis of Dimethyl Oxalate
}

\author{
Hua-wei Liu*), Sheng-tao Qian, Er-fei Xiao, Ying-jie Liu, Jun Lei, Xian-hou Wang, \\ Yu-hua Kong
Gas Purification Division of Haiso Technology Co. Ltd., Hubei Industrial Gas Purification and Utilization Key Laboratory, Wuhan 430074, China.

Received: 30th November 2020; Revised: $2^{\text {nd }}$ January 2021; Accepted: $6^{\text {th }}$ January 2021 Available online: 21 st January 2021; Published regularly: March 2021

\section{Abstract}

On an industrial plant, we observed and examined the ammonia-poisoning catalyst for the synthesis of dimethyl oxalate (DMO). We investigated the catalytic activity in response to the amount of ammonia and revealed the mechanism of such poisoning by X-ray photoelectron spectroscopy (XPS) characterization. Our results show that only $0.002 \%$ ammonia in the feed gas can significantly deactivate the Pd-based catalyst. Two main reasons were proposed: one is that the competitive adsorption of ammonia on the active component $\mathrm{Pd}$ hinders the carbon monoxide $(\mathrm{CO})$ coupling reaction and the redox cycle between $\mathrm{Pd}^{0}$ and $\mathrm{Pd}^{2+}$; and the other is that the high-boiling nitrogen-containing amine compounds formed by reacting with ammonia have adsorbed on the catalyst, which hinders the progress of the catalytic reaction. The deactivation caused by the latter is irreversible. The catalytic activity can be completely restored by a low-temperature liquid-phase in-situ regeneration treatment.

Copyright (C) 2021 by Authors, Published by BCREC Group. This is an open access article under the CC BY-SA License (https://creativecommons.org/licenses/by-sa/4.0).

Keywords: dimethyl oxalate; synthetic catalyst; ammonia poisoning; space-time yield; regeneration

How to Cite: H.-W. Liu, S.-T. Qian, E.-F. Xiao, Y.-J. Liu, J. Lei, X.-H. Wang, Y.-H. Kong (2021). Study on Ammonia-induced Catalyst Poisoning in the Synthesis of Dimethyl Oxalate. Bulletin of Chemical Reaction Engineering \& Catalysis, 16(1), 1-8 (doi:10.9767/bcrec.16.1.9572.1-8)

Permalink/DOI: https://doi.org/10.9767/bcrec.16.1.9572.1-8

\section{Introduction}

The gas-phase synthesis of ethylene glycol based on the oxalate route was firstly industrialized in China [1-2]. At present, an ethylene glycol plant with an annual output of nearly 5 million tons has been conceived, and a promising plant (under construction) is expected to be of an annual output as high as more than 10 million tons per year [3-4]. The process mainly involves a two-step reaction. First, $\mathrm{CO}$ and methyl nitrite $\mathrm{CH}_{3} \mathrm{ONO}(\mathrm{MN})$ are carbonylated to

\footnotetext{
* Corresponding Author.

Email: huaw_liu@163.com (H.W. Liu);

Telp.: +86-27-87408382
}

dimethyl oxalate (DMO) in the presence of $\mathrm{Pd} / \mathrm{a}$ $\mathrm{Al}_{2} \mathrm{O}_{3}$ catalyst, and then with a copper-based catalyst the refined DMO is converted into ethylene glycol (EG) through hydrogenation [5-10]. After more than 50 years of research and more than 10 years of industrialization, this process has gradually matured [11-14]; however, indepth research on industrial applications and reaction processes are still needed. It is difficult for the existing large-scale devices to achieve long-term cycles of full load and stable operation, because the main problem lies in two key factors in the catalyst, i.e. DMO synthesis and hydrogenation [15-18]. For instance, how to further reduce operating costs as for Pd-based synthesis catalyst $[19,20]$, or how to avoid pulveri- 
zation and coking as for copper-based hydrogenation catalysts in order to extend the catalyst life [21].

The catalyst for DMO synthesis is generally a Pd-based catalyst supported by macropores a$\mathrm{Al}_{2} \mathrm{O}_{3}$ [22-25]. The selectivity of such catalyst is usually as high as $99 \%$ or above. The activity is defined by the space-time yield under the conditions of the followings: reaction temperature of $100 \sim 140{ }^{\circ} \mathrm{C}$, space velocity of $2000 \sim 4000$ $\mathrm{h}^{-1}$, and the MN content of $10 \sim 15 \%$. Since the carbonylation between $\mathrm{CO}$ and $\mathrm{MN}$ is a super exothermic reaction and self-decomposition of MN may occur when temperature exceeds 150 ${ }^{\circ} \mathrm{C}$, the focus of the existing research is mainly on the improvement of the catalyst's lowtemperature activity, the control of the reaction process, and the safety of the system [26-30]. There are relatively few basic researches on the application of catalysts [31,32]. For example, the study on the influence of ammonia on synthesis catalysts. Gao and Wu $[33,34]$ have studied on the ammonia poisoning of Pd-based catalysts for the synthesis of DMO. It is believed that $0.54 \%$ of ammonia content only causes a decrease in catalyst activity but does not cause complete deactivation. X-ray photoelectronic energy spectrometer (XPS) and other related characterization analysis revealed that the competitive adsorption of ammonia molecules on the active $\mathrm{Pd}^{2+}$ hinders the oxidationreduction cycle of the latter, resulting in a decrease in catalyst activity. Interestingly, we have observed that in an industrial plant setting the trace amount of ammonia in the $\mathrm{CO}$ gas source leads to significant catalyst deactivation. Furthermore, we combined laboratory simulation and characterization analysis of poisoned catalyst to reveal the mechanism of the poisoning and regeneration.

\section{Materials and Methods}

\subsection{Catalyst Preparation}

The Pd-series catalyst for DMO synthesis was synthesized according to our previous method [35], which was used for a commissioning run test of 200,000 tons per year ethylene glycol industrial plant in 2015. Briefly, spherical $\mathrm{a}-\mathrm{Al}_{2} \mathrm{O}_{3}$ carriers were loaded with $\mathrm{PdCl}_{2}$ through impregnation, and then reduced (by hydrazine hydrate), rinsed, and dried at 120 ${ }^{\circ} \mathrm{C}$.

\subsection{Catalyst Activity Evaluation}

The evaluation of catalyst activity was carried out on atmospheric fixed-bed reaction de- vice: the internal diameter of the stainless steel reaction tube is $8 \mathrm{~mm}$; the catalyst filling volume is $1 \mathrm{~mL}$; the reaction space velocity is $3000 \mathrm{~h}^{-1}$; the reaction temperature is $100 \sim 130$ ${ }^{\circ} \mathrm{C}$; and the carrying gas composition (V/V) is $20 \% \mathrm{CO}+10 \% \mathrm{CH}_{3} \mathrm{ONO}+70 \% \mathrm{~N}_{2}$. We examined the amount of $\mathrm{NH}_{3}$ that is added into the carrying gas and causes catalyst poisoning.

DMO products were collected through condensing the resulting reaction gas and weighted to calculate the space-time yield (STY) index of the catalyst. The composition of reaction gas (pre- and post-reaction) was analyzed using Agilent 7820 gas chromatography, equipped with TCD and FID dual detector, aiming at evaluating the conversion rate of $\mathrm{CH}_{3} \mathrm{ONO}$.

\subsection{Characterization of the Catalyst}

VG Multilab 2000 X-ray photoelectronic energy spectrometer was used to determine the valence state and relative content of the elements on the surface of the catalyst. The test conditions were $\mathrm{Al}$ target, power of $300 \mathrm{~W}$, and pass energy of $25 \mathrm{eV}$. The specific surface area of the catalyst was measured by Anton-Paar Autosorb-1-C-TCD-MS automatic physicochemical gas adsorption instrument, adopting a nitrogen adsorption method. The composition of DMO products (by-products, such as: dimethyl carbonate or methyl formate) were qualitatively analyzed by Thermo Fisher's Trace DSQ II gas chromatography-mass spectrometer.

\section{Results and Discussions}

\subsection{Catalyst Poisoning}

In the September of 2015, a newly built ethylene glycol plant with a production capacity of 200,000 tons per year was commissioned. The plant features a patented technology, i.e. WHB $^{\circledR}$ Coal to Polymer Grade Ethyl Glycol New Technology [36]. Among them, the DMO synthesis system consists of two production lines $(\mathrm{A} / \mathrm{B}$, in parallel), each of which was filled with 50 cubic synthesis catalysts. In the commissioning test run stage, only production line B was deployed to use. After 20 days, the operating load was increased to $80 \%$, and the hot spot temperature of the synthesis reactor stabilized at $117^{\circ} \mathrm{C}$. On the $25^{\text {th }}$ day, we observed that the catalyst activity tended to be declining. After that, the catalyst hot spot temperature needed to be increased by $1{ }^{\circ} \mathrm{C}$ every $1-2$ days to maintain catalyst activity and production load. On the $32^{\text {nd }}$ day, the catalyst hot spot temperature was required to be $125^{\circ} \mathrm{C}$, which 
lasted for the next 4 days. The methyl nitrite conversion rate continued to decrease. On the $36^{\text {th }}$ day, the production load had dropped to $20 \%$ of the full load, and the catalyst was nearly deactivated. The system was shut down for inspection.

It appeared that an acute poisoning on the catalyst was likely attributed to the described performance and the dysfunction of the catalyst. We had investigated the possible causes to the catalyst poisoning on-site. The main indicators of raw materials, including carbon monoxide, methanol, nitric acid, and oxygen, appeared to meet the process requirements. The purification unit in the primary process was found to contain excessive ammonia. The methanol that is used for the low-temperature methanol washing process of the purification unit contains an ammonia mass percentage as high as $0.027 \%$, causing the volume percentage of ammonia in the carbon monoxide feedstock to be $17 \sim 20 \times 10^{-6}(\mathrm{ppm})$. Normally, the standard indicator should be below $0.1 \times 10^{-6}$.

Gao et al. [33] simulated the changes in the activity of the $\mathrm{Pd}$ catalyst for the synthesis of diethyl oxalate (DEO) by the coupling reaction of $\mathrm{CO}$ and ethyl nitrite under different ammonia contents. The results showed that if the ammonia content does not exceed $0.54 \%$ the decrease of the activity of the DEO synthesis catalyst occurred. When the ammonia content reaches $1.16 \%$, the activity decreases rapidly and then the catalyst became inactivated. At the industrial plant setting, however, we have observed that only $0.0017-0.002 \%$ ammonia exceeding the standard can cause significant catalyst deactivation. The effect of different ammonia content on the space-time yield of the $\mathrm{Pd}$ catalyst for the coupling reaction of $\mathrm{CO}$ and methyl nitrite was evaluated at the reaction temperature of 100 and $120{ }^{\circ} \mathrm{C}$ for 3 hours,

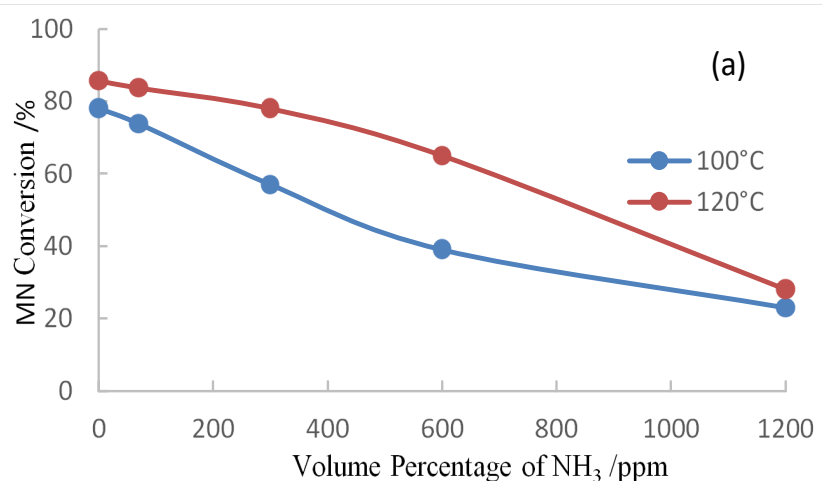

respectively. The results are shown in Figure 1 $(\mathrm{a} / \mathrm{b})$.

As shown in Figure 1, 1200 ppm ammonia content can deactivate the DMO synthesis catalyst within 3 hours. As the ammonia content is reduced to $20 \mathrm{ppm}$, the test results showed that the catalyst activity can be reduced to below 50\% within 12 hours. This indicates that ammonia shows more significant impacts on DMO synthesis catalyst than DEO synthesis catalyst, which is consistent with results from industrial plant testing.

\subsection{Evaluation of the Activity of the Poisoning Catalyst}

We sampled the catalyst in the industrial plant for the synthesis of DMO and evaluated its activity during the poisoning process. Since the DMO synthesis was carried out in a shelland-tube isothermal reactor, the catalyst was packed in the tube with a filling height of $4 \mathrm{~m}$. Therefore, we sampled at different positions in the reactor at different heights for evaluation analysis. Our results showed that no significant difference in catalyst activity among these sampling points (orientations and heights). We conducted laboratory activity evaluation, MN conversion rates, and space-time yields (STYs). For instance, we selected the samples that are $200,800,1500$, and $3500 \mathrm{~mm}$ from the nozzle, which were noted as $\mathrm{A}, \mathrm{B}, \mathrm{C}$, and $\mathrm{D}$, respectively in Figure 2.

It can be seen from Figure 2 that four catalyst samples with different heights show significant decreases in STYs compared with the control sample. The STYs at $100{ }^{\circ} \mathrm{C}$ decreases from $557 \mathrm{~g} / \mathrm{L} \cdot \mathrm{h}$ to $247 \sim 271 \mathrm{~g} / \mathrm{L} \cdot \mathrm{h}$, by about $54 \%$. The STYs at $120{ }^{\circ} \mathrm{C}$ decreased from $698 \mathrm{~g} / \mathrm{L} \cdot \mathrm{h}$ to $516 \sim 537 \mathrm{~g} / \mathrm{L} \cdot \mathrm{h}$, by about $25 \%$. One could conclude that the catalyst demonstrates a uniform deactivation and the low-temperature activity

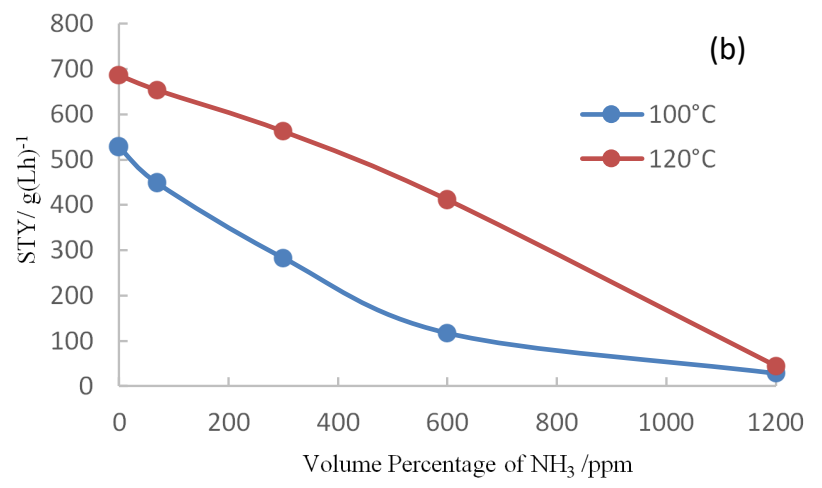

Figure 1. The effect of different ammonia contents on MN conversion (a) and STY (b) of DMO synthetic catalyst 
loss was more significant, which was confirmed by the performance on the industrial plant.

\subsection{Characterization of the Poisoning Catalyst}

X-ray photoelectron spectrometer (XPS) was used to determine the valence state and relative content of the main elements on the surface of the catalyst for the samples (A), (B), and (C) that previously described. The results are shown in Table 1, Figures 3, and 4. The Pd catalyst for the synthesis of HDMO-1 DMO is in the reduced $\mathrm{Pd}$, confirmed by the zerovalent Pd's characteristic peaks of $\mathrm{Pd} 3 \mathrm{~d} 5 / 2$ (binding energy of $335.3 \mathrm{eV}$ ) and $\mathrm{Pd} 3 \mathrm{~d} 3 / 2$ (binding energy of $340.3 \mathrm{eV}$ ) in the control sample (Figure 2). As for the poisoning catalyst samples, the two peaks shift to $336.3 \mathrm{eV}$ and $341.3 \mathrm{eV}$, suggesting the formation of Pd (II). After peak splitting, the electron binding energy peaks of 397.4 $\mathrm{eV}$ and $401.3 \mathrm{eV}$ were observed for Sample (A) in Figure 3. Similar peaks were resembled for Samples (B) and (C), whereas their atomic percentages were reduced by about $50 \%$. Referring to the standards, the nitrogen-containing compound is likely to be $\mathrm{R}-\mathrm{NH}_{2}$ amine substance.

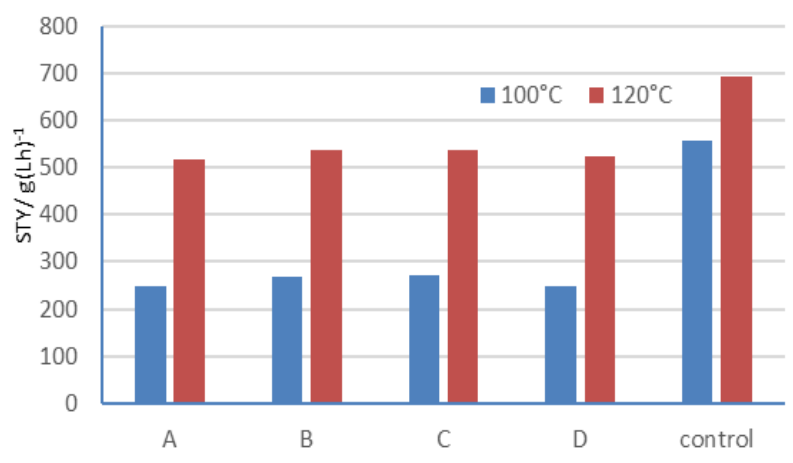

Figure 2. Comparison of the space-time yields of poisoning catalysts (A-D) and controls

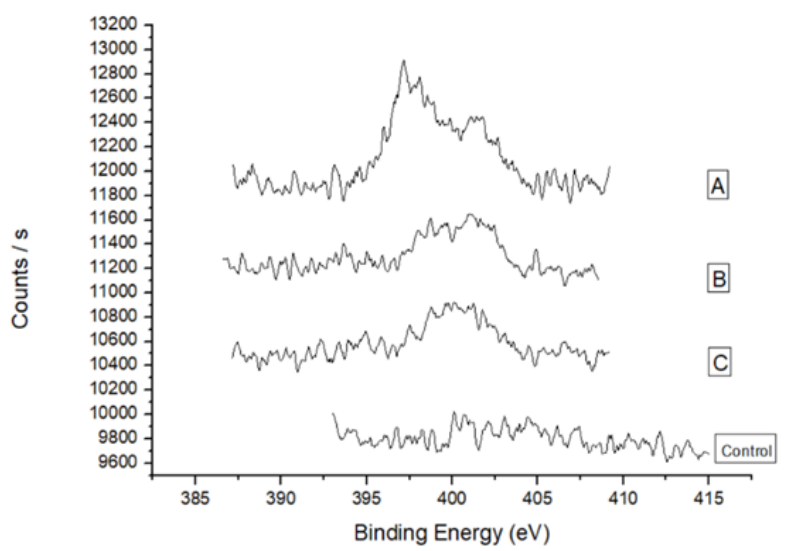

Figure 4. XPS characterization of catalyst surface: N1s
After conducting XPS research on Pd catalyst deactivated by ammonia poisoning in the coupling reaction of $\mathrm{CO}$ and ethyl nitrite, $\mathrm{Wu}$ et al. [34] believe that the competitive adsorption of ammonia molecules on the active component $\mathrm{Pd}^{2+}$ hinders the $\mathrm{CO}$ coupling reaction on the catalyst surface and the redox cycle of the active component $\mathrm{Pd}$, resulting in a decrease in catalyst activity. After the ammonia molecules are desorbed, the activity can be partially restored. The reason for the irreversible ammonia poisoning is that the oxidized $\mathrm{Pd}^{2+}$ can not be reduced in the reaction system and the $\mathrm{Pd}$ coalescence occurs.

In the comparison of poisoning catalyst and the control characterized by XRD (Figure 5), we found no significant difference in the catalyst structure and active component dispersion. No changes in morphology was observed by TEM (images not shown). The observation results were further supported by the fact that we didn't observe the temperature steep rising during the operation. The BET analysis showed that the specific surface area of the poisoned sample was $9.1 \mathrm{~m}^{2} / \mathrm{g}$, which increases by

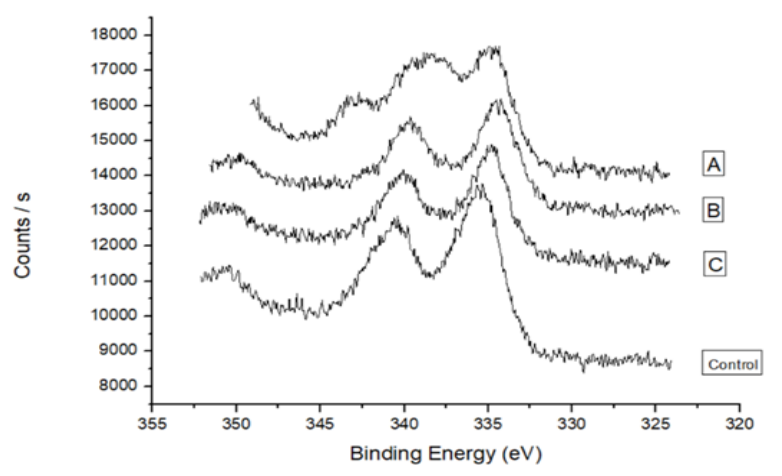

Figure 3. XPS characterization of catalyst surface: $\operatorname{Pd} 3 d$

Table 1. The percentage of atoms of the main elements on the surface of the catalyst

\begin{tabular}{cccc}
\hline Sample & Pd3d & C1s & N1s \\
\hline A & 1.33 & 14.11 & 2.51 \\
B & 1.23 & 7.23 & 1.32 \\
C & 1.32 & 8.50 & 1.15 \\
Control & 1.68 & $/$ & $/$ \\
\hline
\end{tabular}

Note that ND means non-detectable (normally element percentage is below $0.1 \%$ ) 
$71 \%$ in comparison of the control $\left(5.3 \mathrm{~m}^{2} / \mathrm{g}\right)$. The catalyst pore volume was reduced by nearly $10 \%$ after poisoning. Normally the specific surface area and pore volume have a linear correlation. However, the increase of the specific surface area in our plant-scale operation was observed along with a decrease of pore volume. The carrier of the catalyst is a-type alumina, which is a material with large pores and low specific surface area. Some substances may be generated during the ammonia-induced poisoning process, and it appears that they are likely to adsorb onto the surface of the inner pore of the carrier, which may result in a decrease in pore volume and the formation of "false surfaces," leading to an observation of the increase of the specific surface area. Combined with the analysis results, we speculate that some highboiling amine compounds are formed after ammonia enters the reaction system. These substances are adsorbed on the pores and surface of the catalyst and increase the specific surface area of the catalyst. However, the catalyst activity is significantly affected by the binding of ammonia and amine substances with the active ingredient $\mathrm{Pd}$.

\subsection{Regeneration of Inactive Pd Catalysts}

Based on the above-mentioned mechanism of ammonia poisoning, it can be assumed that the catalyst activity should be significantly restored if the amine compounds on the poisoned catalyst are effectively removed. In this case, the method of high-temperature roasting and further reduction can be adopted. $\mathrm{Mu}$ et al. ${ }^{[32]}$ summarized the deactivation and reuse of DMO synthesis catalysts. Chemical plants usually use steam, acid washing, or alkaline washing to remove organic compounds on the catalyst surface at high temperatures. However, in industrial plants, the design temperature of the reactor generally does not exceed $200{ }^{\circ} \mathrm{C}$,
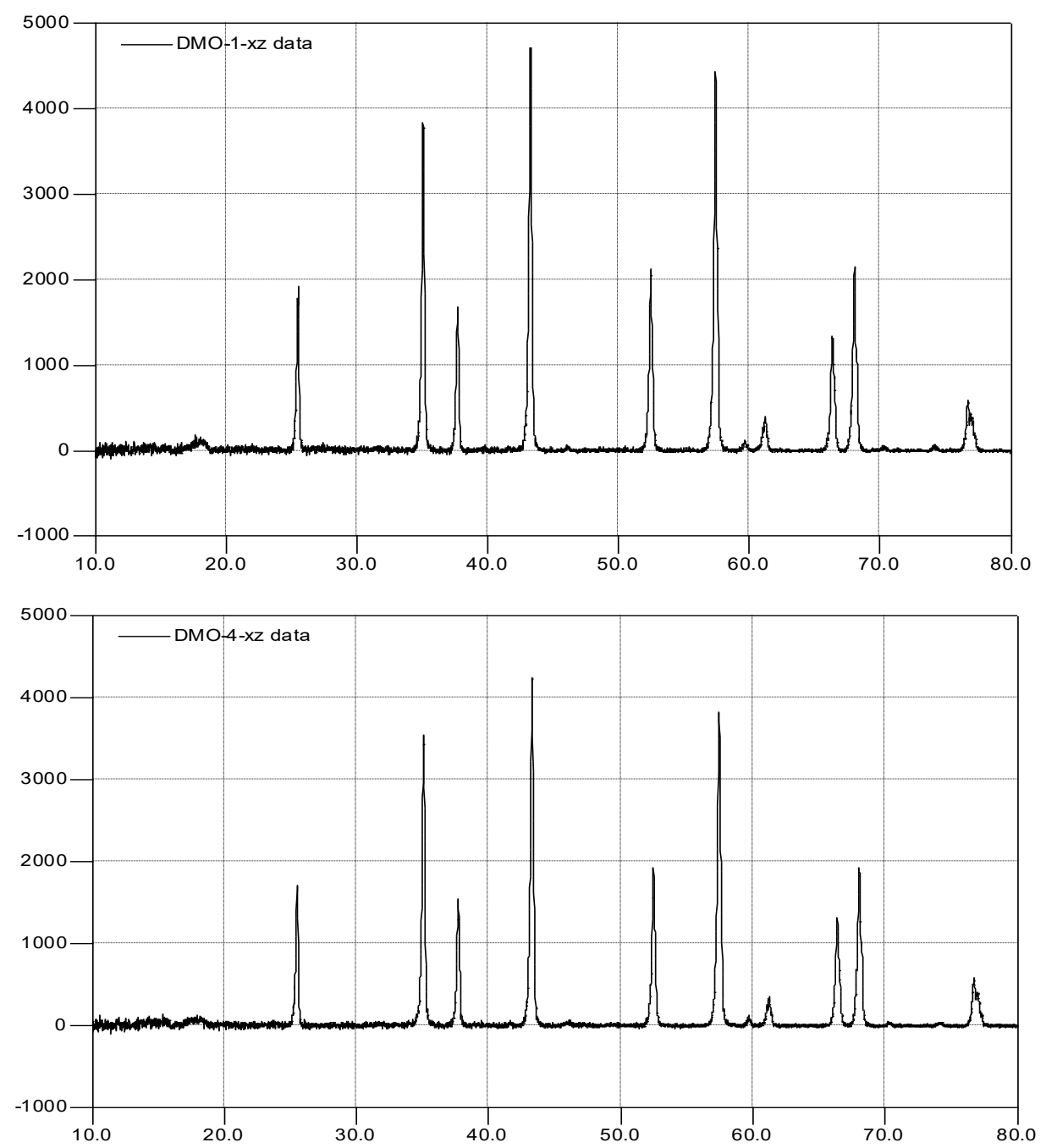

Figure 5. XRD characterization of catalyst surface: poisoning (top) and intact (bottom) catalyst samples 
which makes it difficult to achieve in-situ regeneration in the reactor.

The low-temperature regeneration of the poisoned catalyst was carried out in liquid phase respectively. Sample I to IV were regenerated with formaldehyde, sodium hydroxide solution, ethyl acetate, methanol. Results are shown in Table 2. As shown in the Table 2, the catalyst activity was significantly restored after the regeneration treatment, especially sample IV (100\% restored). Using the method associated with sample (IV) in December 2015, the catalyst used in the B-line with an annual output of 200,000 tons of ethylene glycol was regenerated. The regenerative plant was back to operation in March 2016. The regenerative B-line's performance is equivalent to the intact A-line. The regenerated catalyst's activity has been stable for more than 5 years and can continue to be used. Because low-temperature liquid phase regeneration can significantly restore catalyst activity, the catalyst's irreversible deactivation from ammonia poisoning is mainly caused by the formation of high boiling-point amine compounds that adsorb on the catalyst. Using liquid phase, organic solvent, and lowtemperature regeneration, the $\mathrm{Pd}$ content does not change, because the process of treatment will not have a reaction associated with the catalyst active component $\mathrm{Pd}$.

In comparison to other regeneration methods for ammonia-induced catalysts, our method shows advantages of regeneration efficiency/performance, low energy consumption, and the capability to achieve in-situ regeneration with a plant-scale treatment. The novelty of our method is to develop a low-temperature dissolving technology to remove the high-boiling nitrogen-containing compounds formed by reacting with ammonia.

\section{Conclusion}

The trace amount of ammonia (0.002\%) in the feeding gas can cause significant poisoning and deactivation of the catalyst for DMO synthesis, which is not completely reversible. There are two reasons for the deactivation. One is that the competitive adsorption of ammonia molecules on $\mathrm{Pd}^{2+}$ hinders the $\mathrm{CO}$ coupling reaction and the redox cycle of active $\mathrm{Pd}$ on the surface of the catalyst. This type of deactivation can be restored after ammonia being removed. The other reason is that the adsorption of high-boiling amine compounds produced by the reaction on the catalyst retards the progress of the coupling reaction, which is irreversible. The low-temperature liquid phase regeneration can effectively remove the amine compounds adsorbed on the catalyst, leading to the catalyst activity being completely restored. The method has been applied to our industrial devices. Up to now, the service life of the regenerated catalyst has exceeded 5 years.

\section{Acknowledgment}

This work was financially supported by $\mathrm{Hu}-$ bei Science and Technology Development Project (P20501400001). Thanks to our partners, Wei-jian Chen, Guo-jian Zhang, Jian-yong Shuang, from Wuhuan Engineering Co., Ltd.

\section{References}

[1] Zhou, Z.-F., Li, Z.-J., Pan, P.-B., Lin, L., Qin, Y.-Y., Yao, Y. (2010). Progress in technologies of coal-based ethylene glycol synthesis. Chemical Industry Engineering Progress, 29(11), 2003-2009

[2] Yu, B.-Y., Chung, C.-Y., Chien, I.-L. (2018). Development of a plant-wide dimethyl oxalate (DMO) synthesis process from syngas: Rigorous design and optimization. Computers \& Chemical Engineering, 119: 85-100, doi: 10.1016/j.compchemeng.2018.08.025

[3] Yang, X.-T., Peng, S. (2020). Research and prospect of coal to ethylene glycol industry. Shandong Chemical Industry, 49(1), 46-47, doi: 1008-021X(2020)01-0046-02

[4] Xu, L., Jie, M., Zhao, L.-H., et al. (2018). Pilot test of the catalysts for synthesis of dimethyl oxalate by carbon monoxide coupling. Natural Gas Chemical Industry, 43(6), 80-83

[5] Ye, Z.-G. (2018). The analyses of the coupling reaction mechanism in the process of syngas to ethylene glycol. Yunnan Chemical Technology, 45(10), 88-90

Table 2. The STY of the catalyst after treating by different regeneration methods (I-IV)

\begin{tabular}{ccccccc}
\hline $\begin{array}{c}\text { Temperature } \\
\left({ }^{\circ} \mathrm{C}\right)\end{array}$ & Sample (I) & $\begin{array}{c}\text { Sample } \\
(\text { II })\end{array}$ & $\begin{array}{c}\text { Sample } \\
(\text { III })\end{array}$ & $\begin{array}{c}\text { Sample } \\
(\text { IV })\end{array}$ & Control & Poisoned \\
\hline 100 & 463 & 492 & 524 & 561 & 557 & 247 \\
120 & 598 & 620 & 654 & 692 & 698 & 516 \\
\hline
\end{tabular}


[6] Peng, S.-Y., Yang, L.-S., Liu, Q.-Q., et al. (2017). High active $\mathrm{Pd} / \mathrm{MgO}$ catalyst for $\mathrm{CO}$ oxidative coupling to dimethyl oxalate. Journal of Fuel Chemistry and Technology, 45(8), 963-969

[7] Zhao, T.-J., De, C., Dai, Y.-C., Yuan, W.-K., Holmen, A. (2004). Synthesis of dimethyl oxalate from $\mathrm{CO}$ and $\mathrm{CH}_{3} \mathrm{ONO}$ on carbon nanofiber supported palladium catalysts. Industrial \& Engineering Chemistry Research, 43 (16), 4595-4601, doi: 10.1021/ie030728z

[8] Han, B.-Y., Xue, F., Ling, L.-X., Fan, M., Liu, P., Zhanga, R., Wang, B.-J. (2018). CO oxidative coupling to dimethyl oxalate over Pd-Me $(\mathrm{Me}=\mathrm{Cu}, \mathrm{Al})$ catalysts: a combined DFT and kinetic study. Physical Chemistry Chemical Physics, 20 (10), 7317-7332, doi: 10.1039/C7CP08306H

[9] Zhe, H., Lin, H.-Q., Ping, H., Yuan, Y.-Z. (2011). Effect of boric oxide doping on the stability and activity of a $\mathrm{Cu}-\mathrm{SiO}_{2}$ catalyst for vapor-phase hydrogenation of dimethyl oxalate to ethylene glycol. Journal of Catalysis, 277(1), 54-63, doi: 10.1016/j.jcat.2010.10.010

[10] Yue, H.-R., Zhao, Y.-J., Ma, X.-B., Gong, J.-L. (2012). Ethylene glycol: properties, synthesis, and applications. Chemical Society Reviews, 41(11), 4218-4244, doi: 10.1039/C2CS15359A.

[11] Ma, Z.-Y., Meng, X.-Y., Wang, H.-W., et al. (2009). Progress in research of oxalate synthesis by gas phase catalytic coupling of CO. Petrochemical Technology, 38(4), 456-462.

[12] Uchiumi, S., Ataka, K., Matsuzaki, T. (1999). Oxidative reactions by a palladium-klkyl nitrite system. Journal of Organic Chemistry, 18(2), 3-5, doi: 10.1016/S0022-328X

[13] Zhang, B.-K., Huang, C.-P., Guo, T.-H., et al. (1990). Catalytic synthesis of oxalate diester by carbon monoxide coupling. Chemical Research and Application, 2 (3), 21-25

[14] Lei, H., Wei, X., Du, X.-R., et al. (2019). Study on catalysts for $\mathrm{CO}$ gaseous phase coupling to dimethyl oxalate. Industrial Catalysis, 7(3), 43-46

[15] Qian, L., Yang, J., Jiang, Z.-D., Xiao, W.-D. (2007). Effects of precursors on preparation of $\mathrm{Pd} / \mathrm{a}$-alumina catalyst for synthesis of dimethyl oxalate. Industrial \& Engineering Chemistry Research, 46 (24), 7950-7954, doi: 10.1021/ie070640b

[16] Chen, W.-J. (2018). Analysis on the causes of hydrogenation catalyst chalking and coking in the WHB coal to ethylene glycol technology. Chemical Fertilizer Design, 56(1), 27-29.

[17] Bo, Z., Zhang, S.-H., Hui, S.-G., et al. (2012). Study on deactivation mechanism of $\mathrm{Cu} / \mathrm{SiO}_{2}$ catalyst for hydrogenation of dimethyl oxalate to ethylene glycol. Natural Gas Chemical Industry, 37(4), 1-6.

[18] Xue, F., Ling, L.-X., Cao, Y.-T., Zhang, R.-G., Fan, M.-H., Wang, B.-J. (2018). A DFT study on the catalytic $\mathrm{CO}$ oxidative coupling to dimethyl oxalate on Al-doped core-shell $\mathrm{Pd}$ clusters. The Journal of Physical Chemistry C, 122 (2), 1169-1179, doi: 10.1021/acs.jpcc.7b09272

[19] Xu, L., Jie, M., et al. (2018). Pilot test of the catalysts for synthesis of dimethyl oxalate by carbon monoxide coupling. Natural Gas Chemical Industry, 43(06), 80-83.

[20] Qu, Y.-Q., Yan, W., Li, J.-W., Xu, Q.-X., Liang, X., Jiang, A. (2020). Insights into the $\mathrm{Pd}$ nanocatalysts directed by morphology effect for $\mathrm{CO}$ and methyl nitrite coupling to dimethyl oxalate. Molecular Catalysis, 490: 110949, doi: 10.1016/j.mcat.2020.110949.

[21] Mu, S.-F., Shang, R.-J., Mu, S.-L., et al. (2015). Deactivation reason analysis of copper-based catalysts for hydrogenation of dimethyl oxalate to ethylene glycol. Industrial Catalysis, 23(2), 98-102.

[22] Peng, S.-Y., Xu, Z.-N., Chen, Q.-S., Wang, Z.Q., Lv, D.-M., Sun, J., Chen, Y.-M., Guo, G.-C. (2015). Enhanced stability of $\mathrm{Pd} / \mathrm{ZnO}$ catalyst for $\mathrm{CO}$ oxidative coupling to dimethyl oxalate: Effect of $\mathrm{Mg}^{2+}$ doping. ACS Catalysis, 5 (7), 4410-4417, doi: 10.1021/acscatal.5b00365

[23] Peng, S.-Y., Xu, Z.-N., Chen, Q.-S., Chen, Y.M., Sun, J., Wang, Z.-Q. (2013). An ultra-low $\mathrm{Pd}$ loading nanocatalyst with high activity and stability for $\mathrm{CO}$ oxidative coupling to dimethyl oxalate. Chemical Communications, 49 (51), 5718, doi: 10.1039/c3cc00219e

[24] Wang, S.-P., Xin, Z., Zhao, Y.-J., Ge, Y.-D., Lv, J., Wang, B.-W., Ma, X.-B. (2012). PdFe/a- $\mathrm{Al}_{2} \mathrm{O}_{3} /$ cordierite monolithic catalysts for the synthesis of dimethyl oxalate: effects of calcination and structure. Frontiers of Chemical Science and Engineering, 6 (3), 259-269, doi: $10.1007 / \mathrm{s} 11705-012-1212-6$

[25] Zhao, X.-G., Qian, L., Xiao, W.-D. (2005). Characterization of $\mathrm{Pd}-\mathrm{CeO}_{2} / \mathrm{a}$-alumina catalyst for synthesis of dimethyl oxalate. Applied Catalysis A: General, 284 (12), 253-257, doi: 10.1016/j.apcata.2005.02.004

[26] Qian, L., Yang, J., Tan, J.-Q., et al. (2008). Mechanism of $\mathrm{CO}$ coupling to dimethyl oxalate over $\mathrm{Pd} / / \mathrm{a}-\mathrm{Al}_{2} \mathrm{O}_{3}$. Chinese Journal of $\mathrm{Ca}$ talysis, 29(4) 325-329

[27] Zhao, X.-G., Lv, X.-L., Zhao, H.-G., et al. (2004). Study on $\mathrm{Pd} / / \mathrm{a}-\mathrm{Al}_{2} \mathrm{O}_{3}$ catalyst for vapor-phase coupling reaction of $\mathrm{CO}$ with $\mathrm{CH}_{3} \mathrm{ONO}$ to $\left(\mathrm{CH}_{3} \mathrm{OOC}\right)_{2}$. Chinese Journal of Catalysis, 25(2), 125-128 
[28] Yin, D.-X., Li, Z.-H., Wang, B.-W., et al. (2004). Study of $\mathrm{Pd}-\mathrm{Fe} / \mathrm{Al}_{2} \mathrm{O}_{3}$ Catalyst for $\mathrm{CO}$ coupling to diethyl oxalate. Natural Gas Chemical Industry, 29(2), 20-23

[29] Zhong, N.-X. (2012). Coal to Ethylene Glycol: $\mathrm{Pd}$ nanocatalysts for $\mathrm{CO}$ oxidative coupling to dimethyl oxalate. PhD Dissertation. Chinese Academy of Sciences, Fuzhou, Fujian.

[30] Ling, L.-X., Xue, F., Cao, Y.-T., Liu, P., Fan, M.-H., Zhang, R.-G., Wang, B.-J. (2018). The catalytic CO oxidative coupling to dimethyl oxalate on $\mathrm{Pd}$ clusters anchored on defected graphene: A theoretical study. Molecular $\mathrm{Ca}$ talysis, $453, \quad 100-112, \quad \mathrm{doi}$ : 10.1016/j.mcat.2018.04.021

[31] Gao, Z.-H. (2002). Studies on mechanism of catalytic coupling reaction of $\mathrm{CO}$ and effect of impurities on Catalyst's activity. PhD Disertation, Tianjin University, Tianjin.

[32] Mu, S.-F., Zhang, L.-X., Song, J.-C., et al. (2019). Deactivation and recovery of $\mathrm{Pd} / \mathrm{a}$ $\mathrm{Al}_{2} \mathrm{O}_{3}$ catalyst for gas-phase $\mathrm{CO}$ coupling to dimethyl oxalate. Industrial Catalysis, 27(01), $1-5$
[33] Gao, Z.-H., Qin, W., Fei, H., et al. (2002). Study on ammonia poisoning of $\mathrm{Pd}$ system catalyst for $\mathrm{CO}$ coupling reaction to diethyl oxalate. Chinese Journal of Catalysis, 23 (01), 95-98.

[34] Qin, W., Gao, Z.-H., Fei, H., et al. (2003). XPS study on the deactivated $\mathrm{Pd} / \mathrm{a}-\mathrm{Al} 2 \mathrm{O} 3$ catalyst for CO coupling reaction with ammonia. Journal of Tianjin Institute of Technology, 19 (04), 25-28

[35] Qian, S.-T., Xiao, E.-F., Liu, H.-W., et al. (2015). Pilot test report of HDMO-1 catalyst for the synthesis of dimethyl oxalate. Chemical Fertilizer Design, 53(4), 8-10

[36] Liu, H.-W., Kong, Y.-H., Chen, W.-J., et al. (2014). New technology for production of polymer grade ethylene glycol from coal by using WHB process. Chemical Fertilizer Industry, 41(6), 81-85. 